\section{AB1464-HPR ACUTE EFFECTS OF COLD - PACK APPLIED IN DIFFERENT WAYS FOLLOWING FATIGUE ON POSTURAL STABILITY, PROPRIOCEPTION AND MOTOR PERFORMANCE}

O Aydogdu, Z. Sarı. Physiotherapy and Rehabilitation, Marmara University, Faculty of Health Sciences, Department of Physiotherapy and Rehabilitation, Istanbul, Turkey

Background: There is a lack of literature examining local cooling on postural stability, proprioception, and motor performance following fatigue. Objectives: The purpose of this study was to examine the effects of cold-pack applied on knee joint following fatigue on postural stability, proprioception, and motor performance in healthy subjects. It was hypothesised that fatigue might cause deficits in measurements of postural stability, proprioception, and motor performance and cold-pack treatment applied on knee joint in different ways might prevent this deficit.

Methods: Sixty healthy subjects (33 female, 27 male; age $=22.00 \pm 1.37$ years, height $=169.62 \pm 9.21 \mathrm{~cm}$, weight $=63.48 \pm 12.61 \mathrm{~kg}$ ) were participated in the study. Subjects had no history of lower extremity injury, vestibular or postural stability problems, proprioception problems, hip, knee, and ankle instability. Postural stability, knee proprioception and motor performance were assessed by Pedalo Sensamove System, Biodex System Pro 4, and Stair Climbing Test, respectively.

The subjects were received a clinically-used fatigue protocol on a cycle ergometer. The Modified Borg's Rate of Perceived Exertion Scale has been used for fatigue determination. All assessments were performed three times at rest, immediately after fatigue and cold-pack treatment.

Results: There were no significant changes in terms of postural stability and knee proprioception after fatigue and cold-pack treatment compared to the condition at rest in all groups $(p>0.05)$. However, motor performance was significantly decreased following fatigue compared to the condition at rest $(p<0.05)$.

Conclusions: The hypothesis of this study, that fatigue could cause a deficit in measurement of motor performance was supported. On the other hand, postural stability and proprioception did not decrease following fatigue. According to the results of our study, we concluded that the subjects do not benefit from the use of cold-pack for compensating deficit in measurement of motor performance following fatigue.

Disclosure of Interest: None declared

DOI: 10.1136/annrheumdis-2018-eular.6899

\section{AB1465-HPR IMPACT OF ULCERS IN QUALITY OF LIFE AND FOOT FUNCTION IN SYSTEMIC SCLEROSIS PATIENTS}

R Ghisleni ${ }^{1,2}$, A. Janowska ${ }^{3} .{ }^{1}$ University of Florence, Florence; ${ }^{2}$ Freelance podiatrist, Bergamo; ${ }^{3}$ Department of Dermatology, University of Pisa, Pisa, Italy

Background: Systemic Sclerosis (SSc) is a progressive, highly disabling pathology associated with pain, functional limitation, loss of ability at work and high social costs. Recent studies have proved that quality of life is worst in SSc patients than in healthy people, however there is lack in literaly works investigating ulcers and lower limb complications.

Objectives: The aim of the present study is to investigate health-related quality of life and foot function in patients affected by SSc with or without ulcers.

Methods: 215 patients (mean age 48,6 years SD $\pm 12,3$ ) completed four questionnaires: Short-Form 36 (SF-36) and Health Assessement Questionnaire (HAQ) for quality of life, Foot Fuction Index (FFI) for foot fuction, Cardiff Wound Impact Scale (CWIS) for patients with ulcers only (88). Demographic data were also investigated such as sex, occupation and living place. In addition, further information about type of SSc, age at diagnosis of SSc, age at first Raynaud phenomenon, podiatric assessment and orthopaedic insoles or shoes wear was inquired.

Results: SF-36 scores were significantly lower in patients with ulcers than in patients without ulcers $(p=0,001)$ as regards the physical component score (PCS). PCS was also positively correlated to its own sub-domain Physical Function $(R=0,81)$, Role Physical $(R=0,72)$ and Body Pain $(R=0,71)$. SF-36 Mental component score (MCS) was positively correlated to its own sub-domain Mental Health $(R=0,85)$ and Role Emotional $(R=0,77)$. $H A Q$ scores were significantly higher in patients with ulcers than in patients without ulcers $(p<0,001)$. PCS was negatively correlated to the HAQ $(R=0,75)$. FFI scores were significantly higher in patients with ulcers than in patients without ulcers $(p=0,001)$. CWIS scores were pretty high $(50,6 \%$ SD $\pm 26,6)$. Chi-square-test wasn't statistically significant $(p=0.926)$ : ulcers and age are not correlated. Only 17 patients out of 215 were used to wear orthopaedic footwear, 38 wore foot orthoses and 71 were informed about the figure of the podiatrist.

\begin{tabular}{lccccc}
\multicolumn{6}{l}{ Abstract AB1465-HPR - Table 1. Questionnaire scores and P-value } \\
\cline { 2 - 4 } Group & \multicolumn{2}{c}{ SF-36 } & HAQ & FFI & CWIS \\
\cline { 2 - 4 } & PCS & MCS & & & \\
\hline All patients & $35.78 \pm 10.3$ & $39.40 \pm 11.1$ & $0.90 \pm 0.6$ & $23.16 \% \pm 24.7$ & - \\
Patients with ulcers & $33.0 \pm 9.4$ & $37.7 \pm 11.6$ & $1.11 \pm 0.6$ & $28.9 \% \pm 27.5$ & $50.6 \% \pm 26.6$ \\
Patients without ulcers & $37.73 \pm 10.5$ & $40.6 \pm 10.5$ & $0.74 \pm 0.6$ & $19.1 \% \pm 21.6$ & - \\
P-value & 0.001 & 0.07 & $<0.001$ & 0.001 & - \\
\hline
\end{tabular}

Conclusions: According to the literature, ${ }^{1-2}$ patients with SSc show an impaired quality of life compared to healthy subjects. The majority of patients are unimployed or stay at home due to disability. Furthermore, in case of ulcers, the more pain grows, the more foot function is reduced as well as quality of life gets worse. Wounds could be considered as a biomarker of pathology progression; therefore, clinicians should pay more attention in prevention improving lower limb assessment and treatment.

\section{REFERENCES:}

[1] Rannou F, et al. Assessing disability and quality of life in systemic sclerosis: construct validities of the Cochin Hand Function Scale, Health Assessment Questionnaire (HAQ), Systemic Sclerosis HAQ, and Medical Outcomes Study 36-Item Short Form Health Survey. Arthritis Rheum. 2007 Feb 15;57(1):94-102.

[2] Hudson M, et al.; Canadian Scleroderma Research Group. Quality of life in patients with systemic sclerosis compared to the general population and patients with other chronic conditions. J Rheumatol. 2009 Apr;36(4):76872.

Disclosure of Interest: None declared

DOI: 10.1136/annrheumdis-2018-eular.2387

\section{AB1466-HPR EFFECTS OF SHORT-TERM NEUROMUSCULAR ELECTRICAL STIMULATION ON PAIN, QUADRICEPS MUSCLE STRENGTH, PHYSICAL PERFORMANCE AND KINESIOPHOBIA IN PATIENTS WITH OSTEOARTHRITIS OF THE KNEE (A PRELIMANARY STUDY)}

$\underline{\text { S Aydoğan Arslann }}{ }^{1}$, A. Daşkapan ${ }^{1}$, E.D. Keskin ${ }^{2}$, B.B. Atak ${ }^{3}$, F. KIlıç ${ }^{2} .{ }^{1}$ Department of Physiotherapy and Rehabilitation, Kırıkkale University, Faculty of Health Sciences; ${ }^{2}$ Department of Physical Medicine and Rehabilitation; ${ }^{3}$ Department of Physical Medicine and Rehabilitation, Kırıkkale University Faculty of Medicine, Kırıkkale, Turkey

Background: Osteoarthritis may cause fear of movement, increased pain detention, reduced muscle strength, and range of motion. Quadriceps muscle strengthening is a common goal in the management of knee osteoarthritis. Neuromuscular electrical stimulation (NMES) is considered to be an effective technique for strengthening the quadriceps muscle. It has been used to treat patients with knee osteoarthritis.

Objectives: The aim of the study is to determine the effect of short-term neuromuscular electrical stimulation on pain, strength, physical performance and kinesophobia in patients with knee osteoarthritis.

Methods: 20 patients (9 women 11 men, who were $40-75$ years, diagnosed as stage 2 or stage 3 knee OA according to Kellgren-Lawrence criteria, participated to the study. Socio-demographic data of all individuals were recorded. The cases were randomly divided into two groups as control group $(n=10)$ and study group $(n=10)$. Control group treatment consisted of conventional physiotherapy program (hot pack, transcutaneal electrical nerve stimulation (TENS), ultrasound and home exercises). In the study group, NMES application was added to conventional physiotherapy program. Both groups were treated five days/week for two weeks. The patients were assessed; before and after treatment. The pain was assessed by Visual Analogue Scale (VAS). Muscle strength was assessed by manual muscle test. Stair-climb test was performed to evaluate physical performance. Western Ontorio and McMaster Universities Osteoarthritis Index (WOMAC) was used to assess functional disability. Kinesiophobia was evaluated by Tampa Kinesiophobia Scale.

Results: There was no significant difference between control and study groups in terms of age, Body Mass Index, the scores of VAS value, Quadriceps Muscle strength, Stair-climb test, WOMAC and TAMPA scores at baseline $(p>0.05)$. Post treatment VAS value decreased significantly in both groups compared with pretreatment values $(p<0.05)$. However the scores of Quadriceps Muscle strength, Stair-climb test, WOMAC and TAMPA did not change significantly in both groups after the treatment. When compared the two groups, all the outcomes were similar $(p>0.05)$ after the treatment. 
Conclusions: Because of the preliminary report and less number of patients; drawing definitive conclusions is not possible. It seems that, short-term conventional physiotherapy program decreased only pain, but did not improve strength, physical performance, functional disability and kinesiophobia. Also, we thought that short-term NMES application which added to conventional physiotherapy program did not provide superiority over treatment outcomes.

\section{REFERENCE:}

[1] Bax L, Staes F, Verhagen A. 2005. Does Neuromuscular Electrical Stimulation Strengthen The Quadriceps Femoris? A Systematic Review Of Randomised Controlled Trials. Sports Med 35:191-212.

Disclosure of Interest: None declared

DOI: 10.1136/annrheumdis-2018-eular.4587

\section{AB1467-HPR MEASUREMENT OF CERVICAL PROPRIOCEPTION IN PATIENTS WITH AXIAL SPONDYLOARTHRITIS}

T Ozen ${ }^{1}$, E. Tonga ${ }^{1}$, M.G. Polat ${ }^{1}$, S. Akar ${ }^{2}{ }^{1}$ Physiotherapy and Rehabilitation, Marmara University, Istanbul; ${ }^{2}$ Rheumatology, Katip Celebi University, Izmir, Turkey

Background: Axial spinal inflammation and spinal posture disorders in axial spondyloarthritis (axSpA) may deteriorate proprioception which may be caused by pathologic involvement of spinal entheses containing proprioceptive afferents. ${ }^{1}$ Cervical spine is one of the main inflammation area in axSpA. ${ }^{2}$ Impaired cervical proprioception has negative effects on postural control system. ${ }^{3}$ The cervicocephalic relocation mesure by laser pointer is found a reliable method to measure cervical sensory function in healty participants in a recent study. ${ }^{4}$ And there is limited data that regarding cervical proprioception in axSpA.

Objectives: To examine the differences in cervical joint proprioception between patiens with axSpA and healthy subjects.

Methods: The cervical joint position errors (JPE) were measured to evaluate proprioceptive function accuracy in patients with 29 axSpA and 21 healthy subjects by laser pointer with cervical application. Neutral head position method was used to evaluate proprioception in flexion, extension, rotation and lateral flexion in right and left movement directions at sitting position (figure 1). ${ }^{5}$ Three measures were performed, and the average of the three trials was used for analysis. The distance between zero spot and joint position which patient had been reconstructed was measured by centimetre. Spinal mobility evaluated by BASMI, function evaluated by BASFI and HAQ-S; disease activity defined by BASDAI, pain and fatigue were evaluated by VAS.

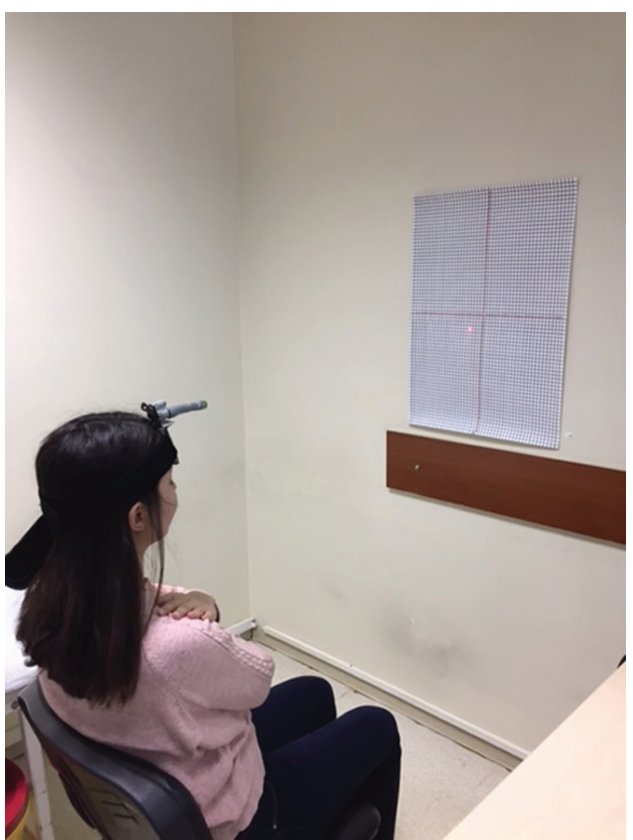

Abstract AB1467HPR - Figure 1
Results: There were 29 patients (21 men, mean ( $\pm S D)$ age; 41.4 \pm 10.9 years) and 21 healthy subjects ( 15 men, mean age $41.1 \pm 11.3$ years) BASMI, HAQ-S and fatigue score were significantly higher in patients (BASMI values were $3.9 \pm 2.3$ vs $1.3 \pm 0.7, \mathrm{p}<0.001$; HAQ-S values were $2.1 \pm 0.8$ vs $0.8 \pm 0.2, p<0.001$; fatigue values were $37.2 \pm 23.3$ vs $16.2 \pm 14.9$ $\mathrm{p}=0.001)$. The comparison of cervical JPE showed significantly larger errors $(p<0.05)$ in patients with axSpa, except right rotation $(p=0.166)$ (table 1).

Abstract AB1467HPR - Table 1

\begin{tabular}{lccc}
\hline Comparison of joint position errors between patients with axSpa and healthy subjects \\
\hline $\begin{array}{l}\text { Variable } \\
(\mathrm{cm})\end{array}$ & $\begin{array}{c}\text { AxSpA patients } \\
(\mathrm{n}=29)\end{array}$ & $\begin{array}{c}\text { Healthy subjects }(\mathrm{n}=21) \\
(\text { mean } \pm \mathrm{SD})\end{array}$ & $\mathrm{P}$ value \\
& $9.88 \pm 6.70$ & $4.66 \pm 3.57$ & \\
\hline JPE in flexion & $12.99 \pm 8.99$ & $5.55 \pm 2.98$ & $\mathbf{0 . 0 0 1}$ \\
JPE in extension & $11.10 \pm 6.56$ & $8.62 \pm 4.41$ & $\mathbf{0 . 0 0 1}$ \\
JPE in right rotation & $10.59 \pm 6.51$ & $7.02 \pm 5.78$ & 0.166 \\
JPE in left rotation & $11.32 \pm 6.53$ & $6.39 \pm 3.54$ & $\mathbf{0 . 0 1 1}$ \\
JPE in right side bend & $9.62 \pm 6.18$ & $6.14 \pm 4.46$ & $\mathbf{0 . 0 0 1}$ \\
JPE in left side bend & & $\mathbf{0 . 0 3 6}$ \\
\hline
\end{tabular}

JPE=Joint position error, $p$ values are based on Mann-Whitney $U$ test.

Conclusions: Cervical joint position sense is impaired in subjects with axSpa. Proprioceptive training may help to boost the effectiveness of rehabilitation

\section{REFERENCES:}

[1] Pompeu JE, Romano RS, Pompeu SM, Lima SM. Revista brasileira de reumatologia. 2012:52(3):409-16.

[2] Madsen OR. Rheumatol Int. 2018. doi: 10.1007/s00296-017-3920-1.

[3] Malmström EM, Fransson PA, Jaxmar Bruinen T, Facic S, Tjernström F. Exp Brain Res. 2017;235(9):2755-2766.

[4] Hatamvand S, Ghiasi F, Asgari Ashtiani A.R, Akbari A, Hossienifar M International Journal of Medical Research \& Health Sciences, 2016, 5, 7S:598-603.

[5] Alahmari K, Reddy RS, Silvian P, Ahmad I, Nagaraj V, Mahtab M. Braz J Phys Ther. 2017;21(4):259-267.

Disclosure of Interest: None declared

DOI: 10.1136/annrheumdis-2018-eular.6320

\section{AB1468-HPR SATISFACTION WITH THE BDMARD ETANERCEPT BIOSIMILAR (SB4) PRE-FILLED PEN AMONG RHEUMATOID ARTHRITIS AND SPONDYLOARTHROPATHY PATIENTS; A GERMAN OBSERVATIONAL STUDY}

U Müller-Ladner ${ }^{1}$, S. Zinke ${ }^{2}$, P.M. Aries ${ }^{3}$, C. Maucksch ${ }^{4} .{ }^{1}$ Abteilung für Rheumatologie und Klinische Immunologie, Kerckhoff-Klinik GmbH, Bad Nauheim ${ }^{2}$ Rheumapraxis Zinke, Berlin; ${ }^{3}$ Rheumatologie im Struenseehaus, Hamburg;

${ }^{4}$ Biogen $\mathrm{GmbH}$, Ismaning, Germany

Background: The TNF $\alpha$ inhibitor etanercept was the first targeted biological disease modifying anti-rheumatic drug (bDMARD) approved for treatment of RA; the first etanercept biosimilar (SB4) was authorised in the EU in January 2016. Various administration devices have been developed for convenient subcutaneous self-injection of bDMARDs including pre-filled pens.

Objectives: This study aims to document general patient satisfaction in day-to-day use of the SB4 pre-filled pen. Patients' experience regarding handling, convenience, other features and the associated training on selfinjection is also evaluated.

Methods: This non-interventional, cross-sectional study is enrolling patients who are treated according to usual medical practice. Patients had experience with the SB4 pre-filled pen in accordance with the prescribing information for at least 3 months prior to completing the onetime standardised patient questionnaire. This study started in August 2017, is ongoing and plans to enrol 500 patients in total from 50 centres across Germany. Subgroup analyses by previous therapy, modality of administration and by indication group are pre-planned.

Results: By November 2017, completed surveys from 142 patients were available for interim analysis. Mean age was 55 years, $61 \%$ were female 